\title{
Preventive Measures against COVID-19 in Pregnancy and Neonates
}

\author{
Paula Candice Alves De Assis Pereira' ${ }^{1}$, Daniele Naiane Domingos Rodrigues ${ }^{1}$, Aline Maria Da Silva Rodrigues ${ }^{1}$, Tatiana Moreira Ferreira', \\ Beatriz Marques Coelho', Mariana Dantas Do Nascimento', Edilson Martins Rodrigues Neto ${ }^{1 *}$, Fernanda Maria Teófilo Campos ${ }^{2}$, \\ Patrícia Leal Dantas Lobo' ${ }^{1}$ \\ 'School of Pharmacy, Dentistry and Nursing, Federal University of Ceará, Fortaleza, Ceará, BRAZIL. \\ ${ }^{2}$ School of Medicine, Federal University of Ceará, Fortaleza, Ceará, BRAZIL.
}

\begin{abstract}
Background: Pregnancy is a delicate state that faces several challenges for physical and mental health, involving physiological, immunological and microbiological aspects to accept and maintain the fetus. In situations of epidemics of infectious diseases, as COVID-19, pregnancy can be a risk factor, due to all the changes caused in physiological and immunological functions, which can increase mortality rates. The lack of therapeutic protocols for this group calls attention to the urgency of developing and standardizing proposals aimed at pregnant women. Objectives: Then we performed a literature review of articles published about pregnancy and coronavirus disease was carried out, mainly through the PUBMED and Web of Science databases. Methods: Thus, articles from systematic reviews, clinical studies and epidemiologic studies, were selected in Portuguese, Spanish and English languages. Results: We selected 20 articles related to
\end{abstract}

the theme in question. There is still no evidence of vertical transmission of the new coronavirus. Conclusion: The literature reports that the interaction between the mother and the newborn should be prioritized and facilitated at the beginning of breastfeeding. This choice must be defined based on the good health of the mother and her newborn child.

Key words: Pregnancy, Coronavirus disease, Breastfeeding.

Correspondence

Dr. Edilson Martins Rodrigues Neto

School of Pharmacy, Dentistry and Nursing, Fortaleza, Ceará, BRAZIL.

Phone: +55 8533660000

Email: edilsonmrneto@hotmail.com

DOI: $10.5530 / j y p .2021 .13 .7$

\section{INTRODUCTION}

Pregnancy is a delicate state that faces several challenges for physical and mental health, involving physiological, immunological and microbiological aspects to accept and maintain the fetus. These adaptations and changes accompany the growth and development of the fetus at different gestational stages. Thus, the success of a pregnancy depended of immune adaptations, both locally and systemically. ${ }^{1}$

In situations of epidemics of infectious diseases, pregnancy can be a risk factor, due to all the changes caused in physiological and immunological functions, which can increase mortality rates. ${ }^{2}$ Studies associate, for example, a higher rate of spontaneous abortion, premature birth and fetal development problems in pregnant women with SARS infection. ${ }^{3}$

In addition, studies during SARS and MERS epidemics show higher numbers of mortality in infected pregnant women when compared to non-pregnant women. Although there are still no large studies with epidemiological data from this group regarding SARS-CoV-2, it is known that this infection has some similarities with SARS-CoV, being even more contagious. The aggravating factor in patients with coronavirus (COVID-19) is that there is still no targeted and effective treatment for the virus and this infection is considered a major challenge for the immune system. ${ }^{4,5}$

Fortunately, the data reported to date, report that the majority of cases of pregnant women diagnosed with COVID-19 have been presenting mild or asymptomatic cases, where only $15 \%$ require artificial respiration. ${ }^{6}$ However, in some cases due to the high level of estrogen and progesterone, the upper respiratory tract tends to dilate, leading to a reduction in the capacity of pulmonary expansion that makes pregnant women susceptible to respiratory pathogens. ${ }^{5}$ Similar to non-pregnant patients, the predominant characteristics of COVID-19 are: fever, cough, dyspnea and lymphopenia. ${ }^{6}$ A study of 12 pregnant and SARSinfected women had as main medical complications respiratory distress, disseminated intravascular coagulopathy, renal failure, secondary bacterial pneumonia and sepsis. ${ }^{7}$

The Brazilian Society of Pediatrics recommends for cases of asymptomatic parturient who do not have home contact with a person with flu syndrome or respiratory infection proven by SARS-CoV-2, timely clamping of the umbilical cord at birth, as well as skin to skin contact. skin and breastfeeding in the newborn's first hour of life. ${ }^{8}$

The lack of therapeutic protocols for this group calls attention to the urgency of developing and standardizing proposals aimed at pregnant women. ${ }^{9}$

\section{METHODS}

To perform this study, a literature review of articles published about pregnancy and coronavirus disease was carried out, mainly through the PUBMED and Web of Science databases. Thus, articles from systematic reviews, clinical studies and epidemiologic studies, were selected in English languages. We selected 18 articles related to the theme in question.

\section{REVIEW OF LITERATURE}

\section{Vertical transmission and coronavirus}

Current evidence indicates that the virus is transmitted only horizontally, with no evidence of vertical transmission from pregnant women to the baby. A recent study by Shanes et al., showed evidence of injuries to the 
placenta of 16 pregnant women who tested positive for SARS-CoV-2. The type of injury seen in the placentas pointed to an abnormal blood flow, with clots in the placenta, between mothers and their babies in the womb, suggesting a new complication of COVID-19. This study also found cases of characteristics of poor maternal vascular perfusion, particularly abnormal or injured maternal vessels and intervillous thrombi, there was also an increase in the incidence of chorangiosis. The injury did not appear to induce negative results in the babies' births. However, the data is limited, requiring further studies on its causes and impacts on the mother and baby. ${ }^{10}$

Recently, in another study, 48 neonates were analyzed and of these, 2 newborns from mothers infected with COVID-19 tested positive for SARS-CoV-2, expressing concerns about the possibility of vertical transmission. However, there was no confirmed case of vertical transmission among the other 46 neonates, reporting absence of coronavirus in amniotic fluid, umbilical cord blood, breast milk and throat swabs. 6 Another from the Children's Hospital of Wuhan in China, collected data from 33 babies and found that 3 (9\%) had early-onset SARS-CoV-2 infection. ${ }^{11}$ Despite the lack of evidence, contamination can occur during birth procedures and therefore all care must be taken to protect the parturient, the fetus and the health team, as reported in a technical note from the Brazilian Society of Pediatrics. ${ }^{8}$

According to the note published by the Ministry of Health, the puerperal woman with suspected or confirmed COVID-19 who underwent cesarean section or vaginal delivery should be released from the hospital environment under a stable clinical and social situation with guidelines to prevent the spread of the virus. As for women diagnosed with COVID-19 after delivery and who are asymptomatic, it is not recommended to extend the hospitalization period and postpone hospital discharge, as long as the mother and the newborn are without signs of flu-like syndrome that can progress to respiratory failure. It is recommended that this should not happen at least before $24 \mathrm{hr}$ after delivery. ${ }^{11}$

A single possible case of mother-to-child vertical transmission was reported by Dong et al. with the baby showing elevated levels of antibodies to SARS-CoV-2 and abnormal levels of cytokines $2 \mathrm{hr}$ after birth. Since IgM antibodies are not transmitted to the fetus via the placenta, the test results suggested that the baby had been infected in the womb and had been exposed to the virus for at least 23 days since the mother's positive diagnosis. ${ }^{12}$

Zeng et al. ${ }^{11}$ and Wang et al..${ }^{13}$ have already reported 2 cases of newborns who tested positive for SARS-CoV-2, which occurred through the family contact they had, that is, greater attention should be paid by the baby's caregiver, to prevent this type of transmission. In Wang et al. ${ }^{13}$ the main manifestations of the disease in newborns were cough and runny nose, for example, indicating respiratory tract infection.

\section{Breastfeeding and coronavirus}

It is known that breastfeeding is strongly associated with an increase in the baby's immunity, especially when performed exclusively until the sixth month of life. ${ }^{14}$

In addition to the concern about the possible consequences of COVID-19 in pregnant women and fetuses, a major concern is related to the potential effect that inadequate management of the mother-newborn dyad and interruption of breastfeeding can bring. ${ }^{15}$

Doctors who recently dealt with the COVID-19 epidemic in China suggest infant formula feeding or possibly donor breast milk. ${ }^{13}$ The authors do not provide specific reasons for this choice, without information from any general assessment of the risks of infection compared to those who do not breastfeed. ${ }^{15}$
The Brazilian Society of Pediatrics recommends that breastfeeding be maintained as long as the mother wishes to breastfeed, be in adequate conditions for this and practice preventive measures at the time of breastfeeding, such as wearing a mask; hygiene measures, such as hand washing and cleaning objects for milk extraction, such as pump pumps. ${ }^{8}$ According to the WHO, a mother with suspicion, probable or confirmed as to COVID-19 can practice contact and exclusive breastfeeding with her child, unless her health is compromised, in which case she should be encouraged to express milk to meet her needs. Baby's food habits. ${ }^{15}$

Finally, the Academy of Breeding Feeding Medicine proposes two options for hospital management of puerperal women with COVID-19 or suspected cases: accommodation or separation between mother and newborn, a choice that should involve the health conditions and decision of the woman. ${ }^{16}$

\section{DISCUSSION}

Gestational follow-up through prenatal consultations is a crucial preventive service to improve results and prevent damage to the health of mothers and babies. With the rise of COVID-19 cases and the demand for social distance, the need for a new assistance model arose, restricting personal meetings to the essential services identified in the guidelines and making the form of care that was predetermined more flexible. Based on evidence, these services can be delivered in less than 14 visits and do not require that all appointments are made in a personal way, favoring the use of telemedicine and the development of dynamic methods for this monitoring. ${ }^{17}$

In a pandemic, social distance conducts prove to be effective in reducing disease transmission. Obstetric care can follow this model without prejudice, simplifying medical care providers. ${ }^{6}$

The literature points to the occurrence of transmission of cases in the pediatric population, however at very low levels and without evidence that is due to vertical transmission. This can be explained by the lower social contact that babies are exposed to, when compared to adults, being less exposed to direct contact and consequently to a transmission route. ${ }^{18}$ Although some studies indicate the interruption of breastfeeding for COVID-19 mothers as preventive measures, it can be seen that this indication has no scientific evidence regarding transmission so far. ${ }^{15,19}$

The Center for Disease Control (CDC) recommends that if the mother is under investigation or has a positive result for COVID-19, the first choice option should be separation, this decision not being based on the impact this may have breastfeeding. In the case of separation from the mother and the newborn, the routine use of breastmilk substitutes should be avoided; it is advisable to implement the extraction, transport and administration of fresh milk from mother to newborn. ${ }^{15}$

An important question arose regarding the anesthetic therapy used in cesarean deliveries of pregnant women with COVID-19. A study of 17 pregnant women, using continuous epidural or combined spinolepidural (ECE) anesthetic techniques as the first choice, in order to avoid endotracheal intubation and (providing for the possibility of inducing or worsening pulmonary complications in these women with COVID-19) and anesthesia general as an option for cases of maternal or fetal infection, emergencies, patients with contraindications to epidural or ECE techniques and any previous failures. The results report that 3 patients (18\%) received general anesthesia (with endotracheal intubation) and the other 14 patients (82\%) received continuous epidural anesthesia. $86 \%$ of pregnant women submitted to epidural anesthesia had a higher rate of intraoperative hypotension compared to the general anesthesia group. The intraoperative hemodynamic parameters were not improved with the change to the left lateral position or with the vasoconstrictor 
treatment. There were no other apparent clinical divergences between the general and epidural anesthesia groups. ${ }^{20}$

Davanzo et al. ${ }^{15}$ point out that a mother with symptoms of severe respiratory infection (such as fever, cough and respiratory secretions) and unable to care for the newborn should be separated, pending the test result for COVID-19. If the test is positive, mother and child continue to be managed separately; if the test is negative, accommodation for the dyad is applicable as long as the mother is ready to care for the newborn.

\section{CONCLUSION}

There is still no evidence of vertical transmission of the new coronavirus. The literature reports that the interaction between the mother and the newborn should be prioritized and facilitated at the beginning of breastfeeding. This choice must be defined based on the good health of the mother and her newborn child.

\section{CONFLICT OF INTEREST}

The authors declare that there is no conflict of interest.

\section{REFERENCES}

1. Mor G, Aldo P, Alvero AB. The unique immunological and microbial aspects of pregnancy. Nature Reviews Immunology. 2017;17(8):469.

2. Gujski M, Humeniuk E, Bojar I. Current State of Knowledge About SARS-CoV-2 and COVID-19 Disease in Pregnant Women. Med Sci Monit. 2020;26:e924725.

3. Wong SF, Chow KM, Leung TN, Ng WF, Ng TK, Shek CC, et al. Pregnancy and perinatal outcomes of women with severe acute respiratory syndrome. American Journal of Obstetrics and Gynecology. 2004;191(1):292-7.

4. Lu X, Zhang L, Du H, Zhang J, Li YY, Qu J, et al. SARS-CoV-2 Infection in Children. New England Journal of Medicine, 2020;382(17):1663-5.

5. Liu H, Wang LL, Zhao SJ, Kwak-Kim J, Mor G, Liao AH. Why are pregnant women susceptible to COVID-19? An immunological viewpoint. J Reprod Immunol. 2020;139:103122.

6. Dashraath P, Wong JLJ, Lim MXK, Lim LM, Li S, et al. Coronavirus disease 2019
(COVID-19) pandemic and pregnancy. Am J Obstet Gynecol. 2020;222(6):521-31.

7. Rasmussen SA, Smulian JC, Lednicky JA, Wen TS, Jamieson DJ. Coronavirus Disease 2019 (COVID-19) and pregnancy: What obstetricians need to know. Am J Obstet Gynecol. 2020;222(5):415-6.

8. Brazilian Society of Pediatrics. Recomendações para Assistência ao Recémnascido na sala de parto de mãe com COVID-19 suspeita ou confirmada. 2020.

9. LaCourse SM, John-Stewart G, Adams WKM Importance of inclusion of pregnant and breastfeeding women in COVID-19 therapeutic trials. Clin Infect Dis. 2020;71(15):879-81.

10. Shanes ED, Mithal LB, Otero S, Azad HA, Miller ES, Goldstein JA. Placentalpathology in COVID-19. 2020;154(1):23-32.

11. Zeng LK, Tao XW, Yuan WH, Wang J, Liu X, Liu ZS. First case of neonate infected with novel coronavirus pneumonia in China. Chin J Pediatr. 2020;58(1):E009.

12. Dong L, Tian J, He S, Zhu C, Wang J. Possible Vertical Transmission of SARSCoV-2 From an Infected Mother to Her Newborn. JAMA. 2020;323(18):1846-8.

13. Wang J, Wang D, Chen GC, Tao XW, Zeng LK. SARSCoV-2 infection with gastrointestinal symptoms as the first manifestation in a neonate. Chin $\mathrm{J}$ Contemp Pediatr. 2020;22(3):211-4.

14. Zielinska MA, Sobczak A, Hamutka J. Breastfeeding knowledge and exclusive breast-feeding on infants in first six months of life. National Institute of Public Health. 2017;68(1):51-9.

15. Davanzo R, Moro G, Sandri F, Agosti M, Moretti C, et al. Breastfeeding and coronavirus disease-2019: ad interimindications of the italian society of neonatology endorsed by the union of European neonatal and perinatal societies. Maternal and Child Nutrition. 2020;e13010.

16. Academy of Breastfeeding Medicine. 2020. < https://www.bfmed.org/>

17. Peahl AF, Smith RD, Moniz MH. Prenatal Care Redesign: Creating Flexible Maternity Care Models through Virtual Care. Am J Obstet Gynecol. 2020;223(3):1-10

18. Rodríguez MR. SARS-COV-2: Una mirada al paciente pediátrico. Acta Odontológica Venezolana. 2020;58(1):7-8.

19. Favre G, Pomar L, Qi X, Nielsen-Saines, K, Musso D, Baud D. Guidelines for pregnant women with suspected SARS-CoV-2 infection. The Lancet Infectious Diseases. 2020;20(6):652-3

20. Chen R, Zhang Y, Huang L, Cheng BH, Xia ZY, Meng QT. Safety and efficacy of different anesthetic regimens for parturients with COVID-19 undergoing Cesarean delivery: A case series of 17 patients. Sécurité et efficacité de différents modes d'anesthésie pour des parturientes infectées par la COVID-19 accouchant par césarienne: Unesérie de 17 cas. Can J Anaesth. 2020;67(6):655-63.

Article History: Submission Date : 21-11-2020; Revised Date : 25-12-2020; Acceptance Date : 21-01-2021

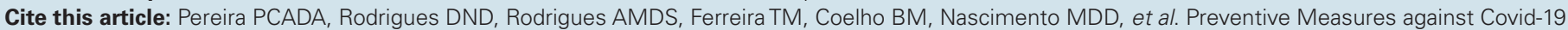
in Pregnancy and Neonates. J Young Pharm. 2021;13(1):31-3. 